\title{
Risk, harm and intervention: the case of child obesity
}

\author{
Michael S. Merry $\cdot$ Kristin Voigt
}

(C) Springer Science+Business Media Dordrecht 2013

\begin{abstract}
In this paper we aim to demonstrate the enormous ethical complexity that is prevalent in child obesity cases. This complexity, we argue, favors a cautious approach. Against those perhaps inclined to blame neglectful parents, we argue that laying the blame for child obesity at the feet of parents is simplistic once the broader context is taken into account. We also show that parents not only enjoy important relational prerogatives worth defending, but that children, too, are beneficiaries of that relationship in ways difficult to match elsewhere. Finally, against the backdrop of growing public concern and pressure to intervene earlier in the life cycle, we examine the perhaps unintended stigmatizing effects that labeling and intervention can have and consider a number of risks and potential harms occasioned by state interventions in these cases.
\end{abstract}

Keywords Obesity · Children · Intervention - Stigma · Risk · Parental autonomy

In February 2012 Child Protection Services in the Netherlands placed three children directly under state supervision because their weight was considered a serious threat to their health. The oldest child, then thirteen, had a body mass index (BMI) of 34.4 (the average for this age being 21).

M. S. Merry $(\square)$

Department of Educational Sciences and Department of Philosophy, University of Amsterdam, Amsterdam,

The Netherlands

e-mail: m.s.merry@uva.nl

K. Voigt

Institute for Health and Social Policy \& Department of Philosophy, McGill University, Montreal, QC, Canada
The middle child, then eleven, was found to be overweight but not obese, while the youngest, then only six, also was found to be obese. The parents in the case, both Turkish immigrants, insisted that they were themselves quite concerned and that they had requested professional support. Following the advice of a family doctor, they previously had enrolled their children at a nearby fitness facility. However, this seemed to have had little effect on the children's weight; indeed, their youngest child had gained weight. In reviewing the case, the judge determined that the parents had not done "enough" and that the children would need to be supervised by state appointed social workers until their weight could come down to an "acceptable" level. After 6 months, the case would again be reviewed. ${ }^{1}$

The Dutch case is not unique; similar reports about obese children being removed from their families to be placed in foster care have emerged from the $\mathrm{US}^{2}$ and Australia, ${ }^{3}$ and there have been suggestions that we are likely to see an increase in the number of such cases. These interventions reflect valid worries about child obesity but also hint at some of the normative issues involved when states seek to address these worries. While some prominent obesity experts—-such as Murtagh and Ludwig (2011) support the case for these kinds of interventions in at least some instances, they have remained highly controversial

\footnotetext{
$\overline{1}$ Though the initial intervention received national attention, the details of the follow-up were not made known to the public.

2 http://blog.cleveland.com/metro/2011/11/obese_cleveland_heights_ child.html; http://www.ctvnews.ca/should-parents-lose-custody-ofseverely-obese-kids-1.669804; http://www.nytimes.com/2001/07/08/ magazine/08ANAMARIE.html? scp=1\&sq=obesity\%20aceves $\% 20$ belk in\&st=cse.

${ }^{3}$ http://www.news.com.au/national-news/victorian-authorities-removeobese-children-removed-from-their-parents/story-fndo4eg9-1226424 413140 .
} 
and no consensus has emerged on whether-and, if so, under what conditions - they might be justified. In this paper, we examine the philosophical issues surrounding these kinds of interventions, paying particular attention to the implications of two issues that are not always appreciated in this debate: parental autonomy and weight stigma.

As we proceed, we join others in examining the characteristics of obesity, including its known causes and health risks. Yet unlike those who are keen to ramp up pressure to intervene in cases of child obesity, we demonstrate that enormous ethical complexity is prevalent in child obesity cases. This complexity, we argue, favors a cautious approach. Further, against those perhaps inclined to blame neglectful parents, we argue that laying the blame for child obesity at the feet of parents is simplistic once the broader context is taken into account. We also show that parents not only enjoy important relational prerogatives worth defending, but that children, too, are beneficiaries of that relationship in ways difficult to match elsewhere. Finally, against the backdrop of growing public concern and pressure to intervene earlier in the life cycle, we examine the perhaps unintended stigmatizing effects that labeling and intervention can have and consider a number of risks and potential harms occasioned by state interventions in these cases.

\section{Childhood obesity: a straightforward case for intervention?}

Rates of overweight and obesity have been increasing among children in developed countries. Recent estimates suggest that almost $32 \%$ of US children and adolescents are overweight or obese (Ogden et al. 2012). In Europe, too, childhood obesity prevalence appears to be increasing, with around $30 \%$ of UK and Spanish school children being overweight or obese (Manios and Costarelli 2011). Given the health risks associated with childhood obesityincluding increased rates of type 2 diabetes, fatty liver disease with cirrhosis, obstructive sleep apnoea, cardio respiratory compromise and a variety of orthopaedic problems - these developments continue to receive an increasing amount of attention from public health experts. With growing concerns about the childhood obesity 'epidemic' and its effects on children, policy-makers have been seeking effective interventions to address the problem. Predictably, parents and their responsibilities have been at the forefront of the debate: what can they do to ensure their child maintains a healthy weight, and in what ways have they 'failed' if the child does become obese?

Cases such as that of the Turkish-Dutch family we described above may seem like a clear-cut case for state intervention. An intervention broadly describes a coordinated effort to prevent or interrupt some kind of unfavorable behavior or set of behaviors. The principles governing coercive state intervention in the domain of public health entail promoting the safety and welfare both of those believed capable of directing their own lives, and of those who are not. Safeguarding the interests of children falls into the latter category and it is the doctrine of parens patriae which succinctly captures a state's legal right and moral obligation to protect those unable to protect themselves. ${ }^{4}$ Beyond the essentials for subsistence-food, drink and shelter-children have an interest in being loved and accepted, receiving nurture and guidance, and also a certain degree of discipline and structure. In most cases it is parents who supply these to their own children in one degree or another, and-excluding clear cases of abuse or neglect - there is no obvious correlation (beyond requirements of basic care such as food and shelter) between specific parenting styles and a child's well-being. However, states often play an important supportive role by establishing and maintaining institutions that facilitate or promote goods like public health, education and employment while also monitoring, at least to some extent, parents' actions and their ability to live up to their responsibilities towards their children.

How should we think about the risks and harms resulting from childhood obesity, and on what basis, if any, do these risks and harms justify interference with parents' choices over their children? Does child obesity qualify as a case warranting state intervention with a view to protecting and/ or promoting the interests of the child? Should obesity among children be treated, for instance, like cases of abuse or neglect, as some have argued ${ }^{5}$

At first glance, these questions seem like a straightforward application of Mill's harm principle, according to which power may be used to constrain people's actions to prevent harm to third parties. The relevant third parties in this case are children who may be harmed by their parents' actions (or omissions). However, as we will demonstrate, the issue is far more complex than that. In what follows, we first examine the various risks and harms associated with

\footnotetext{
${ }^{4}$ In many cases this doctrine is associated with paternalism. Coercive interference with the liberty of $P$ in order to protect $P$ or promote $P$ 's interest is how paternalism is classically understood. Yet broader conceptions of paternalism are available. For instance, coercive interference with $P$ in order to protect $Q$ can be motivated both by paternalist and non-paternalist reasons. Depending on its justification, coercively restricting what one agent can do in order to protect and/or promote the interests of another may constitute a paternalist action. Sometimes this is labelled 'impure' or 'indirect' paternalism in the literature, but we will not pursue these matters further here.

5 See for example http://abcnews.go.com/blogs/health/2011/11/27/ obese-third-grader-taken-from-family-placed-in-foster-care/; and also http://www.dailymail.co.uk/news/article-2069986/Child-taken-careobese-Parents-didnt-control-weight.html.
} 
obesity and ask whether these things justify state intervention. Then, to appreciate the complexity of the issues involved, we examine, first, questions around family autonomy, and, second, the role of various environmental factors that appear to contribute to childhood obesity. Next we assess the risks of aggravating stigma associated with labelling, and finally the risks associated with interventions themselves. Though we are sensitive to the health risks correlated with child obesity, owing both to the vulnerable position of the child, as well as to the significant risks of exacerbating harm in cases of state intervention, we highlight a number of complexities surrounding these kinds of interventions and caution against their use. In cases where state intervention is warranted, we argue that they must be sufficiently attentive to the child's physical but also emotional health, family autonomy, as well as other factors in the obesogenic environment.

\section{Harms and risks}

First, while the harm principle starts from the assumption of a life-threatening, imminent harm that can be prevented through intervention, questions of harms, risks and the likelihood of preventing harms through interventions are much more complex.

In the area of public health, as in other domains, many interventions are reactive, i.e., they occur after a problem has manifested, for example, after evidence of abuse or neglect comes to light. Again, this reflects the state's $p a-$ rens patriae prerogative, which is to prevent or reduce harm, even if acted upon only as a last resort. Interventions of this sort involve a variety of strategies where the aim may vary from damage control or minimization to a more structured rehabilitation and restoration to some previous, more favorable, state.

One clear advantage of a reactive intervention is that the problem is already rendered explicit: its features can be diagnosed, its effects traced and monitored, and strategies to counter or minimize its continuation can be planned and implemented with varying degrees of success. On the other hand, there are considerable disadvantages to a reactive tactic. Indeed, reactive interventions are an extremely difficult undertaking with highly variable rates of success given the extent to which health and safety conditions may have already deteriorated. Lifestyles to which persons have become habituated, or health conditions involving addiction, contribute to these challenges. This is particularly true when both the contextual features of one's environment, together with the choices others have made, so profoundly shape and to a considerable degree even determine (both genetically as well as behaviorally) specific_arguably irrevocable-outcomes (e.g. psychological harm incurred in early childhood).

Especially in the case of young children, a reactive intervention will certainly strike many of us as an instance of 'too little too late': better to try as much as possible to prevent neglect or abuse from occurring in the first place than to respond after the damage has been done. Indeed, given the number of risks and harms associated with early childhood, increasingly there is talk of early intervention whose aim - as the label suggests-is not merely to react but rather to prevent unfavorable or risk-related experiences from occurring in the first place. In order to prevent harm or unfavorable outcomes, specific risks are targeted and labeled, populations more likely to manifest those risks are identified, and initiatives are undertaken. Early or preventative interventions include simple monitoring of the situation (hence not directly interfering), to providing information and advice, to offering incentives such as free classes aimed at promoting 'good parenting'. Similarly, in public education systems many countries employ a variety of methods aimed at promoting good health, regular exercise and healthy lifestyle choices.

To try and prevent harm from materializing, states also may resort to various forms of regulation, for example restricting what and how products can be put on the market (as in New York City mayor Michael Bloomberg's attempt to restrict the sale of large sodas), or how companies can market these goods (as in the UK's restrictions on advertising of foods to children). Taxation and subsidies, too, may have an ameliorative effect on public health, although decisions about which products to tax or subsidize remain hotly contested issues, and, where it has been tried (most recently in Mexico $^{6}$ ), the 'fat tax' has not yet been very effective. $^{7}$ In more extreme cases states may impose fines for irresponsible behavior, or remove children from their parents' custody and place children in foster care when there is explicit evidence of abuse or neglect.

Given concerns about the health risks associated with child obesity, public health experts understandably would like to see more done by the state to prevent harm from occurring. But there are numerous intricate challenges here. For example, there is uncertainty around what kinds of interventions might help overweight or obese children reduce their weight to a 'healthy' level. A wide range of interventions have been discussed and implemented, such

\footnotetext{
${ }^{6} \mathrm{http}: / / \mathrm{www} \cdot$ theguardian.com/sustainable-business/mexican-cokesugar-tax-health.

7 Denmark was the first country to introduce a 'fat tax', but its effectiveness was found to be wanting because consumers simply went to nearby Sweden or Germany to stock up on those same products at a much lower price. The tax was abolished after only 1 year. See http://www.washingtonpost.com/blogs/wonkblog/wp/ 2012/11/13/denmark-scraps-worlds-first-fat-tax/.
} 
as those seeking to improve the quality of food provided in schools or increase provision of drinking water over sugarsweetened beverages; interventions that provide information to parents about healthy nutrition; or interventions that increase the availability of safe outdoor play areas. However, researchers have generally been disappointed by how little impact these types of interventions tend to have, and in spite of intensive, ongoing research, effective interventions have remained elusive.

How do these considerations affect the case for intervention in situations such as the Dutch one described earlier? In many instances, including the Dutch one, we are primarily concerned with the risk of harm rather than clearly impending harms that we are seeking to prevent. That is to say, even before harm occurs, there is risk that harms may occur, and the presence of risky behaviours itself may allow certain steps to be taken that can minimize or prevent harm. We join others in welcoming a variety of programs that aim to promote good health and minimize health risks. However, in what follows we argue that serious challenges arise not only in detecting when these risks are present, but also in assessing how serious they are, whether the presence of risks is reliably predictive of harm occurring in a significant number of cases, and also whether interventions aimed at preventing risk will themselves be efficacious.

Making such assessments in the case of childhood obesity is an unusually complex task. 'Overweight' and 'obesity' categories are defined in relation to body mass index (BMI), which is based on a person's weight and height. For adults, BMIs above 25 and 30 are now standardly taken to indicate overweight and obesity, respectively. These categorisations, of course, come with various problems. Weight reflects both muscle mass and body fat, and the health risks associated with body fat also appear to vary depending on its location and type; these are not considerations that can be captured within the BMI.

With children, the development of meaningful categories of 'overweight' and 'obesity' poses further problems. The most common method of classification relies on growth charts that compare children's weight to that of children of the same age and sex; specific centiles are then chosen as cut-off points to categorise children as obese or overweight. In the US, for example, children whose weight is above the 85th centile of the appropriate reference group are considered overweight, whereas those who are above the 95th centile are considered obese. Unlike for adults, however, these categories do not relate to health risks associated with particular weight categories; commentators have noted that the cut-offs are 'essentially arbitrary' (Cole and Rolland-Cachera 2002, p. 15).

As we have seen, obesity involves a number of serious health risks and harms. But evaluating risk is easier said than done. For some very obese children, health concerns may have already materialized; they may have already developed type 2 diabetes, for example. But many harms are not imminent; they may occur far in the future. This inclines many to argue that if harm is about to occur we shouldn't have to wait until it has materialized before we intervene. On the other hand, the nature of 'risk' is that the harm is uncertain: it may or may not actually occur, and the outcome may be more or less severe.

Uncertainty is a particular problem in the childhood obesity context. As we mentioned above, the ways in which children are categorized as 'overweight' or 'obese' is not closely tied to what we know about health risks associated with increased levels of body fat. Moreover, the system used to classify individuals as overweight was designed as an epidemiological tool to be used to monitor developments at the population level and does not allow for conclusions about the risks faced by particular individuals: BMI categories are explicitly not meant to be used in clinical contexts or as diagnostic tools (Nicholls 2013). That a child is considered 'overweight' or 'obese' according to the measurement scales most commonly used does not allow for conclusions about any particular risks the child may be facing. The difficulties of determining specific health risks speak in favour of relying on an imminent harm standard and erring on the side of caution rather than intervening too soon.

\section{Parental autonomy}

A second consideration that complicates the question of whether or not states should intervene in families when children become obese is that there are legitimate concerns about family autonomy. As we have seen, in most cases children are better off with their own parents given the unconditional love their parents lavish on them, but also their need for nurture and discipline. Parents, too, have important interests tied up with family life. Parents arguably have a strong interest in developing relationships with their children, which will involve bringing them up in particular ways (Brighouse and Swift 2006; Overall 2012; Thomas 2005). Of course no parent has absolute rights over their own children; they are independent beings with unique preferences and interests (Schapiro 2003). Yet unless there is compelling evidence to show that parents are failing to meet their children's basic needs, liberal democratic principles accord parents a great deal of latitude in raising their children as they see fit. Further, unless there are compelling reasons to interfere in the private sphere, societies governed by liberal democratic principles must facilitate a great deal of pluralism, normally taken to extend to a range of voluntary associations, but also a 
variety of beliefs, perspectives and life pursuits. Pluralism will entail not only different cultural practices and political opinions but also parenting styles, food choices, and body sizes.

Interference with parents therefore isn't costless: it potentially involves restricting parents' choices with respect to their own children. Many of the concerns relevant to childhood obesity, such as choices about food and children's spare time activities, are areas that parents may consider important elements of their parenting activities. This is not to say that parents' choices are impervious to criticism or intervention when the health or safety of the child is seriously at risk. It is to say, however, that parents—and the family generally—normally enjoy important prerogatives with respect to how their own children are brought up. As a general rule, then, perfectionist models of parenting are problematic, and the threshold for justifiable interference with parents' choices is rather high.

Interestingly, countless activities parents engage in seem to arouse little objection, even when they arguably entail risks for children that are comparable to those one may associate with being overweight or obese. For example, many parents bring their children up to conform to religious beliefs, customs and behavior even when the threat of indoctrination is present; many parents allow their children to play contact sports, even when it is widely known that the risks of serious injury or death are significant; many parents allow their children to watch considerable amounts of television even when there are risks of attention deficit and possibly other socially inhibitive effects. These kinds of examples illustrate how common 'risky' behavior often is associated with parental decisions (or, more controversially, parental failings), which nonetheless do not typically warrant outside interference. The same also may be true in child obesity cases, and, in any case, coercive state interventions whose aim is to reduce a child's risk or to improve his/her circumstances will be fraught with difficulties.

\section{Parents and the obesogenic environment}

Third, we must carefully consider how questions about the causes of childhood obesity should inform the debate. A very simplistic account of these causes simply points to an imbalance of energy expended in relation to the energy 'taken in': if we consume more calories than is required to maintain our level of physical activity, we gain weight; we lose weight when energy expended exceeds the amount consumed. But this account glosses over the more complex question of what factors influence how much energy individuals consume and expend. On the one hand, many commentators focus on individuals' choices: after all, it is individuals who choose what and how much to eat, and whether and how much to exercise. On the other hand, commentators highlight the factors shaping those decisions and the ways in which the environments in which we live constrain or facilitate particular choices. Among these factors we might include poverty, family history and genetic disposition, media, education, sleep patterns, work schedules and environments, sedentary lifestyles, access to transportation and the availability and affordability of healthy food. Any and all of these can contribute to diminished control over our choices.

With respect to childhood obesity, the focus is often on the choices that parents make on behalf of their childrenparticularly in relation to their children's nutrition (e.g. do parents provide heavily processed foods or are meals prepared from scratch?) and their physical activity (e.g. are children allowed or encouraged to play outside?). Again, however, much of the discussion around childhood obesity highlights the importance of understanding the factors that shape parents' choices. The environments in which we live are increasingly seen as significant causal contributors to obesity, both among children and adults (e.g. Swinburn and Egger 2002). The term 'obesogenic environment' describes particular aspects of the environment that are conducive to overconsumption of energy and/or the under-exertion of energy through physical activity. For children, researchers have highlighted factors as far-ranging as food marketing targeted at children, lack of playgrounds and safe spaces for outdoor activity, food available in schools, and less emphasis on physical education in schools.

Factors of the obesogenic environment will make it much harder for parents to ensure a healthy lifestyle for their children (Holm 2008). Parents often find their efforts to promote a healthy lifestyle for their children frustrated by the obesogenic environment in which they live: food marketing creates desires among children for foods that are highly processed and high in 'empty' calories; unsafe neighbourhoods and lack of playgrounds can make it difficult to ensure an appropriate level of physical activity; the (lack of) quality food in many school lunch programs may reinforce bad habits; in some neighbourhoods there is an absence of healthy food priced affordably (also known as 'food deserts').

Obesogenic environments can interfere with the choices that parents would like to make on behalf of their children. For example, many parents will oppose their children's becoming accustomed to the highly processed foods, sweets and drinks that food companies promote in ways that appeal to children. But one of the strategies pursued by the food industry is to rely on children's 'pester power': even if young children do not buy their own food, they can 'pester' their parents to buy these foods for them. The way marketing campaigns create desires for particular brands or foods among children-e.g. by using cartoon characters to 
promote them-may well interfere with the choices parents would like to make. The obesogenic environment may therefore interfere with parental autonomy and parents' interest in making decisions about important aspects of their children's lives. The obesogenic environment is problematic not only because of its effects on children but also because it interferes with or frustrates choices that parents may legitimately make on behalf of their children (Voigt et al. 2014).

The situation is complicated further by the fact that it is disadvantaged families-in particular families from ethnic minority or low-income groups-who are disproportionately subject to factors of the obesogenic environment: they often have more restricted access to fresh foods than wealthier families (Walker et al. 2010), poor neighbourhoods often offer fewer opportunities for physical activity (Lovasi et al. 2009), and poor parents have fewer resources available to pay for physically active free-time activities. Social disadvantage also becomes apparent in many of the real-world cases where obese children were removed from their parents. For example, a mother whose obese son was moved into her sister's care reports having to work two jobs to make ends meet and not having the time to cook. ${ }^{8}$ Disadvantage also became a concern in the Dutch case we discussed earlier, where the parents found it difficult to navigate the welfare system in a foreign language.

How do these concerns affect the question of when state intervention might be appropriate? The mere fact that the obesogenic environment makes it harder for parents to ensure a healthy lifestyle for their children does not entail that they do not have a duty to 'try'. However, the importance of the environment suggests that ensuring that children maintain a healthy weight is a responsibility shared by several actors, among whom parents are only one (Voigt et al. 2014). Regarding cases of child obesity as a purely individual or parental failing - and as an issue that must be addressed, in extreme cases, by removing the child from the parents' care-does not give appropriate weight to the context that constrains the choices parents can make about their children's care. This is one aspect in which obesity is very different from the kinds of cases that are normally considered as child protection issues.

Interestingly, part of the argument to support intervention in the Dutch case was that the parents involved ostensibly had not done 'enough' to reduce the weight of their children. It seems appropriate that child protection agencies would seek to determine whether or not parents have made a genuine effort to address a problem affecting the child's welfare; taking children out of the parents' care only makes sense when parents are 'failing' to live up to

\footnotetext{
8 http://www.ctvnews.ca/should-parents-lose-custody-of-severelyobese-kids-1.669804.
}

their basic responsibilities towards their children. In the case discussed, however, the parents had sought medical assistance and enrolled their children in a sports club, suggesting that they were taking steps to address the situation. The fact that their children's weight had not been reduced (insofar as this can even be correctly determined while a child is still growing) despite their efforts is not surprising: research with adults suggests that weight loss is notoriously difficult to achieve and any successes are often not long-lasting (Simpson et al., 2011). Therefore it is crucial that the child's weight not be used as an indicator of whether or not parents have done 'enough'. Further, the difficulties of achieving weight loss and the likelihood of subsequent weight gain make it inappropriate to use the child's weight to determine when the child can be returned to the parents' custody and to assess how 'well' the child is doing subsequently.

\section{Stigma and labeling}

Fourth, any discussion of (childhood) obesity must proceed from an appreciation of how moralised the discourse around obesity is and the significant stigma that attaches to it. Unlike other health conditions (e.g. asthma, polio or arthritis), obesity typically is seen as the inevitable result of bad choices, and obese individuals are depicted-implicitly or explicitly - as blameworthy. In most cultures obesity also deviates from cultural norms about acceptable body size and shape. Hence in addition to known health risks associated with obesity, it also comes with a stigma. By stigma we refer to a badge of shame, an identity marker imposed by others and for which strong disapproval is both expressed and believed to be justified. Stigmas lend themselves to public attitudes of disgust, ridicule and social exclusion. It captures something important about the way persons are treated by members of majority or dominant groups because of some marker or attribute they have, though it is the significance others ascribe to those markers that produces the stigma in the first place. The experience of discrimination and social exclusion is often at least partly explained by the prior existence of stigma, and the role that various media play is crucially relevant to creating and perpetuating mainstream attitudes about what is "normal' and acceptable.

While a number of other stigmas have diminished over time as a result of more education or interactive experience, in the twenty-first century it is fair to say that the stigma of obesity continues to countenance much derision with impunity (Puhl and Heuer 2009, 2010; Ten Have et al. 2010). As we indicated earlier, much of this is likely to derive from the fact that obesity is considered to be simply a consequence of behavior or lifestyle choices. This 
propensity also can be found among those arguably better informed than most. Proffering a kind of "stigmatization lite," bioethicist Daniel Callahan (2013) recently argued that we can use the social stigma of obesity to positive effect, just as is often done in the context of anti-smoking campaigns, Predictably his suggestion raised the ire of some readers for the personal blame that it strongly implied. Of course, as with any individual health issue there is a degree of personal responsibility involved, if not for preventing a health problem, then certainly with how one responds to it. Yet reducing obesity to a 'lifestyle choice' fails to take the complex variety of contributing factors into account, and if we do that we risk not only misdiagnosing the problem but also causing more harm than good.

Further, the consequences associated with stigmatization imply that the harms of obesity are not limited to the physical realm. Overweight and obese persons routinely deal with verbal abuse from their peer groups, the public at large and even their own families (Neumark-Sztainer et al. 2002). Studies suggest that psychological harms are incurred as well (Dixon 2010). Making matters worse, evidence repeatedly has been marshaled demonstrating discrimination against overweight and obese persons in the workplace. Concerns about stigma or disrespectful treatment can even lead overweight and obese persons to avoid health professionals and delay utilization of preventative care (Puhl and Heuer 2009).

Children in particular are vulnerable here owing to their limited psycho-social development and profound dependency on the adults in their lives. Harm inflicted early in life has long-term effects, and mitigating the effects of that harm once the damage has been done, or once persons have become habituated to those effects, is extraordinarily difficult. Teasing, bullying and other forms of physical and emotional torment are a routine affair for those who stand out from the 'norm'. There is evidence showing that even children of a very young age (as young as three years old) exhibit disapproval of other children they consider to be fat (e.g. Harriger et al. 2010, Davison and Birch 2004). These cumulative harms are insidious, and not only because they contribute to low self esteem. Not infrequently taunts and ridicule about the shape of one's body reinforce poor health choices and also may lead to more social isolation, depression and even thoughts about suicide (Eisenberg et al. 2006). The upshot is that risks already associated with obesity can be aggravated when stigma attaches to it.

What are the implications of weight stigma for obese children in the matter of state interventions? First, it is crucial that we are cautious of our own biases and how they might affect our views on these interventions, and of how those making decisions about specific interventions may be susceptible to such biases. Since even health care professionals have been found to have biases against obese patients (e.g. Puhl and Brownell 2001), there is little reason to assume that those making decisions about family interventions would be any less liable to weight stigma and prejudice. If we have negative views of obese children and/ or view them as solely responsible for their weight, this may incline us to accept interventions that carry negative implications for the children involved. Similar effects may come into play if weight-based stigma affects our perspective on the parents of obese children.

Second, we must be aware of how interventions into families can contribute to the stigmatization of obese children and their families. State interventions should seek to reduce, rather than contribute to, the stigmatization of obese children and adults. Yet even with the best of intentions, efforts to improve public health can lead to singling out of vulnerable populations and attributing blame. And while it remains rare, the 'message' associated with interventions that remove obese children from their families is an overly simplistic one that is likely to cast parents in an exceedingly negative light.

Minority groups, many of which already are stigmatized owing to poverty, language deficits or visible differences, are susceptible to further harm in these cases. Child obesity is more common among socioeconomically disadvantaged families; such families are also more likely to experience high levels of stress. Stress can be particularly acute for those who in addition to financial hardship also must deal with the stresses of being stigmatized. Given the high correlation in Western societies between poverty, minority status and obesity, there is considerable risk of adding to the stigma such families already experience.

Again, as we have just seen, professionals whose concern is with minimizing risk are not immune to criticism. Indeed, here is where we encounter not only the risks in the population that experts believe are predictive of problematic behaviors, but also risks that are created by those in positions of authority when they label, target and intervene in family life with the aim of protecting children from harm. As Wikler (2002, p. 55) observes, "a policy of health promotion that assigns the wrong kind and wrong degree of responsibility to the individual could be disastrous for health $[\ldots]$ the appeal of the notion of personal responsibility masks an ideological vulnerability that is ripe for exploitation."

Hence interventions that involve the removal of a child from parental custody must meet exacting standards and should only occur as an absolute last resort. Certainly to justify such radical actions in child obesity cases, there would need to be conclusive evidence that health risks were imminent, that such an intervention would likely produce a positive outcome, and finally that no better alternatives were available (Varness et al. 2009). Yet even 
if all of these criteria are met, individual cases must be assessed separately and there still will be good reasons to proceed very cautiously. Except in the most extreme cases, it is likely unwise to remove young children from their own parents for very long. Rather, every effort should be made to support the parents and limit the child removal to as short a time as possible.

\section{Intervention and risk}

Let's return to the Dutch case described earlier. Recall that this was a case of state intervention in a case of child obesity in which the children were placed directly under state supervision with the aim of monitoring and improving their health. A number of things about this case are noteworthy and troubling. In the first place, the reported BMIs mentioned in the case (35 for the eldest child) did indeed seem alarming; several health and legal professionals certainly were of the opinion that serious health risks were present. Yet whether the relevant health risks can reliably predict specific health outcomes for these children is another matter. As we have seen, the mere presence of obesity in itself is not sufficient to establish or predict imminent harm (Varness et al. 2009). For instance, many obese children do not grow up to be obese adults. Further, many obese persons do not develop the health problems most commonly associated with obesity.

Second, Dutch Child Protective Services (hence an authoritative state agency) viewed this as a case of serious parental neglect. Meanwhile, the lawyer for the family argued that the mother had asked for support or advice from a social worker, yet in her broken Dutch her request was translated as a desperate cry for intervention. Child Protection Services was promptly called in. Third, the parents' lawyer argued that more than 4 months after Child Protection Services had intervened, the family still had received no professional support. Fourth, at the time conservative estimates were that roughly 3,000 other twelveyear-olds in the Netherlands were considered obese and countless other children are seriously overweight. While there certainly are precedents for state intervention for child obesity in other places, it is relatively rare, and it certainly was precedent-setting in the Netherlands. ${ }^{9}$ Of course we cannot extrapolate from this one case to know how analogous cases might play out, but by examining this case we certainly have an indication of what can go wrong, even in a country well known for all sorts of health-related interventions.

\footnotetext{
$\overline{9}$ http://www.nrc.nl/nieuws/2012/06/08/jeugdzorg-stelt-te-dikke-kin deren-onder-toezicht/.
}

Now even if many readers recognize and concede these ethical complexities, there still will be those who may ask: but given the increased risk of developing some welfarereducing health problem in the future, why wait until the harm is imminent? Surely early intervention with the aim to prevent or reduce risk and harm in the first place is a better approach. We, too, are sympathetic to these concerns and are mindful of the related health risks. Moreover, we certainly agree that a variety of interventionist approaches can be adopted to support and enable parents. So with respect to child obesity, the state can play an important role, for example, in restricting what advertisers are permitted to do, or in subsidizing certain foods. Moreover, better education, financial support, respite services (already available in many locations for parents with disabled children), and other types of structured programs can contribute to positive and effective outcomes.

At the same time, we have argued that there are limits in our ability to detect risk and to assess how serious it is. Risk and harm may be correlated but causal connections are far less clear. Recall that a BMI categorization in itself is not a reliable diagnostic tool for predicting harm. Recall too, as we saw in the Dutch case, how labeling and targeting certain populations in an attempt to head off risk can actually aggravate risk, even as health professionals seek to minimize it. So not only are there risks of exacerbating harm, positive outcomes following from early interventions are not a foregone conclusion, for even when the motivation is to reduce risk, the actual outcome may not go as planned. Ours is not an argument against constructive interventions tout court. Rather the point is simply that interventions whose aim is to curb childhood obesity must proceed with extreme caution.

Social workers and volunteers often find themselves at the frontline of decision-making about how best to interpret complex situations. Yet it is vitally important that distinctions are drawn between any of the following: proven problems caused by chronically failing parents; challenges with a temporary crisis; a possible illness or disorder with the child, possible harbingers of problems of a high predictive value (like an addiction); and more general characteristics as well that may be strongly correlated with obesity, such as dwelling in a particular neighborhood. Interventions inattentive to any of the foregoing items risk exacerbating existing problems or creating new ones.

A final consideration that should inform our response to childhood obesity and questions about intervention in families with obese children is the likelihood of such interventions actually improving children's health and well-being, once we take a broader perspective. It has long been recognized that more radical state interventions in cases involving children are extremely contentious, in part because the harm incurred by the intervention itself (e.g. 
foster care) threatens to cause more serious damage than that which it aims to prevent. Nearly forty years ago Michael Wald (1975, p. 993) observed: "there is substantial evidence that, except in cases involving very seriously harmed children, we are unable to improve a child's situation through coercive state intervention. In fact, under current practice, coercive intervention frequently results in placing a child in a more detrimental situation than he would be in without intervention." These concerns continue to be valid today.

Further, in some communities, distrust of states for failing to adequately inform the public or for abuses of its authority in the past for failing to procure consent also fuels a great deal of skepticism against state officials who claim to know what is best for their citizens. Hillary Rodham (1973, p. 513) writes that the sentiment "against state intervention stems from the state's poor record in caring for children removed from their families." She continues:

...the unchecked discretion of the state has vices of its own. The best interests standard, initially followed in most state interventions and explicitly used as a standard for adjudicating children's interests in proceedings evaluating parental care, is not properly a standard. Instead, it is a rationalization by decisionmakers justifying their judgments about a child's future, like an empty vessel into which adult perceptions and prejudices are poured (ibid).

Even when motivated by the child's welfare, where the aim of an intervention is to protect the child's present and future interests, interventions perceived either to be arbitrary or unlawfully intrusive to family life will be perceived as heavy-handed and illegitimate. Hence for both moral (but also practical) reasons, both of these concerns underscore the fact that state interference must be one of last resort.

Given the foregoing risks associated with intervention in cases of child obesity, we would argue that the following are of paramount importance. In the first place, the interest of the child must guide all judgments and decisions about intervention in obesity cases, recognizing that any individual child's interest is not exclusively determined by obesity-related health concerns. What may be in one child's interest often will not line up with the interests of other children, even when they share similar health risks. Second, in the overwhelming majority of cases children are better off with their own parents not only because parents are in most cases better positioned to understand and unconditionally love their own children; as the earlier remarks of Wald make clear, there also is evidence showing that only in the worst cases of neglect or abuse are the interests of children well served by removing them from their parents' custody. Third, when evidence of imminent harm or neglect can be unequivocally demonstrated, parents can and should be supported in productive ways allowing for development and improvement. Fourth, in aiming to protect and promote the welfare of its citizens, states must take care not to single out particular groups for special attention in ways that seem arbitrary and discriminating. Indeed, even when issues of legitimacy are not at stake, the effects of state policies may in fact exacerbate matters for those said policies are intended to ameliorate. Finally, as we have seen, to safeguard the legitimacy of its aims to protect and promote the interests of it citizens, whether they are seen as being capable or incapable of looking after their own interests, state interference must be one of last resort.

\section{Conclusions}

In this paper we have examined the strong correlation between obesity and risk to health. We also have examined the complexity of factors involved in the occurrence of obesity, in particular in connection to the obesogenic environment. We also have discussed why interfering with parents in this context when their children's weight is considered unhealthy is highly problematic. Interference is problematic both on a principled as well as a practical basis.

On a principled basis, interventions are often considered on the basis of perceived risk rather than actual or impending harms; such risk is extremely difficult to assess and evaluate. The cost of interfering with parents' interest in deciding important aspects of their children's lives should also be appreciated when considering these interventions. It also must not be forgotten that in most societies obesity comes with a stigma, and unless great care is taken to properly diagnose and support families, interventions whose aim is to prevent or curb obesity risk aggravating that stigma. Indeed, targeting certain populations arguably more susceptible to obesity produces risks of its own.

On a practical basis the needs of most children are better met by supporting parents and leaving children right where they are. This does not mean that large disparities in child welfare are morally acceptable, or that the obesogenic environment should be left as it is. But beyond ensuring that the basic thresholds of child welfare are met, the difficulties of intervention are formidable when applying welfare and harm standards to the general public without engaging in arbitrary-and likely class-based-value judgments towards others seen to be making unacceptable lifestyle choices. Even if these trappings could be avoided, no state has the resources to consistently and successfully intervene in family life with the aim of fostering better outcomes. 
Notwithstanding the real health concerns related to child obesity, we have argued for proceeding cautiously. In particular, interventions that aim to remove children from the home environment must meet exacting standards and must only occur as an absolute last resort. This seems correct given the special relationship most children have with their own parents and the risks of exacerbating harm such interventions often entail.

Again we wish to reiterate the role states can play in these matters. There is much that states can and should do much to curb risks associated with child obesity. Indeed, state interventions may take various forms, most of which should be supportive and non-intrusive. These may include providing free education about health and exercise, but also subsidizing healthier food and improving its availability in poor neighbourhoods. And of course we should not only focus on interventions as these pertain to overweight or obese children; public attitudes and prejudices are every bit as much an object of concern. Societal prejudices influence which demographic groups are targeted but also which decisions are taken and how they are implemented. More can be done to alter how the public thinks about and behaves toward those whose body sizes do not conform to accepted norms.

In short, as attention to obesity continues to grow, we will need to be vigilant about the different risks and harms at stake. These include the possible health risks associated with obesity, the costs of interfering with parents' choices about important aspects of their and their children's lives, and finally the enormous costs and challenges associated with efforts to alter the obesogenic environment. Indeed, even when the aim of state-initiated interventions is to promote the health and safety of young children, both the range of possible interventions as well as the potential obstacles are considerable.

\section{References}

Brighouse, H., and A. Swift. 2006. Parents' rights and the value of the family. Ethics 117(1): 80-108.

Callahan, D. 2013. Obesity: Chasing an elusive epidemic. Hastings Center Report 43(1): 34-40.

Cole, T.J., and M.F. Rolland-Cachera. 2002. Measurement and definition. In Child and adolescent obesity, ed. W. Burniat, T.J. Cole, I. Lissau, and E.M.E. Poskitt, 3-27. Cambridge: Cambridge University Press.

Davison, K., and L. Birch. 2004. Predictors of fat stereotypes among 9-year-old girls and their parents. Obesity 12(1): 86-94.

Dixon, J.B. 2010. The effect of obesity on health outcomes. Molecular and Cellular Endocrinology 316(2): 104-108.

Eisenberg, M., D. Neumark-Sztainer, J. Haines, and M. Wall. 2006. Weight-teasing and emotional well-being in adolescents: longitudinal findings from Project EAT. Journal of Adolescent Health 38(6): 675-683.
Harriger, J., R. Calogero, D. Witherington, and J. Smith. 2010. Body size stereotyping and internalization of the thin ideal in preschool girls. Sex Roles 63(9): 609-620.

Holm, S. 2008. Parental responsibility and obesity in children. Public Health Ethics 1(1): 21-29.

Lovasi, G.S., M.A. Hutson, M. Guerra, and K.M. Neckerman. 2009. Built environments and obesity in disadvantaged populations. Epidemiologic Reviews 31(1): 7-20.

Manios, Y., and V. Costarelli. 2011. Childhood obesity in the WHO European region. In Epidemiology of obesity in children, adolescents: Prevalence, etiology, ed. L.A. Moreno, I. Pigeot, and W. Ahrens, 43-68. New York: Springer.

Murtagh, L., and D. Ludwig. 2011. State intervention in lifethreatening childhood obesity. Journal of the American Medical Association 306(2): 206-207.

Neumark-Sztainer, D., N. Falkner, M. Story, C. Perry, and P.J. Hannan. 2002. Weight-teasing among adolescents: correlations with weight status and disordered eating behaviors. International Journal of Obesity and Related Metabolic Disorders 26(1): 123-131.

Nicholls, S. 2013. Standards and classification: A perspective on the 'obesity epidemic'. Social Science and Medicine 87: 9-15.

Ogden, C., M. Carroll, B. Kit, and K. Flegal. 2012. Prevalence of obesity and trends in body mass index among US children and adolescents, 1999-2010. JAMA: The Journal of the American Medical Association. 307(5): 483-490.

Overall, C. 2012. Why have children? The ethical debate. Cambridge: MIT Press.

Puhl, R.M., and K. Brownell. 2001. Bias, discrimination, and obesity. Obesity Research 9(12): 788-805.

Puhl, R.M., and C.A. Heuer. 2009. The stigma of obesity: A review and update. Obesity 12(5): 941-964.

Puhl, R.M., and C.A. Heuer. 2010. Obesity stigma: Important consideration for public health. American Journal of Public Health 100(6): 1019-1028.

Rodham, H. 1973. Children under the law. Harvard Educational Review 43(4): 487-514.

Schapiro, T. 2003. Childhood and Personhood. Arizona Law Review 45: 575-594.

Simpson, S.A., C. Shaw, and R. McNamara. 2011. What is the most effective way to maintain weight loss in adults? British Medical Journal 343: d8042.

Swinburn, B. and G. Egger. 2002. Preventive strategies against weight gain and obesity. Obesity Reviews 3(4): 289-301.

Ten Have, M., I. de Beaufort, and S. Holm. 2010. No Country for fat children? Ethical questions concerning community-based programs. In Preventing childhood obesity: Evidence policy and practice, ed. E. Waters, B. Swinburn, J. Siedel, and R. Uauy, 31-39. Oxford: Blackwell.

Thomas, L. 2005. The family and the political self. Cambridge: Cambridge University Press.

Varness, T., D. Allen, A. Carrell, and N. Fost. 2009. Childhood obesity and medical neglect. Pediatrics 123(1): 399-406.

Voigt, K., Nicholls, S. and Williams, G. 2014. Childhood obesity: Ethical and policy issues. Oxford University Press.

Wald, M. 1975. State intervention on behalf of 'neglected' children: A search for realistic standards. Stanford Law Review 27(4): 985-1040.

Walker, R.E., C.R. Keane, and J.G. Burke. 2010. Disparities and access to healthy food in the United States: A review of food deserts literature. Health and Place 16(5): 876-884.

Wikler, D. 2002. Personal and social responsibility for health. Ethics and International Affairs 16(2): 47-55. 